\title{
Implementation of the Australian national hand hygiene initiative
}

\author{
AJ Stewardson ${ }^{1 *}$, PL Russo', M Cruickshank², ML Grayson', \\ Hand Hygiene Australia and the National Hand Hygiene Initiative \\ From 3rd International Conference on Prevention and Infection Control (ICPIC 2015) \\ Geneva, Switzerland. 16-19 June 2015
}

\section{Introduction}

In 2008, the Australian Commission on Quality and Safety in Health Care (ACSQHC) engaged Hand Hygiene Australia (HHA) to implement the National Hand Hygiene Initiative (NHHI), a national approach to hand hygiene $(\mathrm{HH})$ culture change adapted from the WHO Multimodal HH Improvement Strategy.

\section{Objectives}

To achieve sustained improvements in $\mathrm{HH}$ performance amongst healthcare workers, reduce healthcare-associated infections, develop an effective education and credentialing system about $\mathrm{HH}$ and infection control, and make $\mathrm{HH}$ and infection control core business for all healthcare institutions.

\section{Methods}

$\mathrm{HHA}$, the ACSQHC, and jurisdictional authorities collaborated to support healthcare institutions implement the NHHI. At institution level, core components of the NHHI are alcohol-based handrub at the point-of-care, healthcare worker education, and $\mathrm{HH}$ auditing with performance feedback using the WHO '5 Moments' methodology. HHA developed an implementation manual, profession-specific e-learning modules, $\mathrm{HH}$ auditor training workshop materials, a web-based database for monitoring and reporting $\mathrm{HH}$ performance and other resources. Since 2011, the interim national benchmark for $\mathrm{HH}$ compliance has been $70 \%$, and aggregate institution-level compliance has been reported publically online. In 2013, implementation of the NHHI became a hospital accreditation requirement.

${ }^{1}$ Hand Hygiene Australia, Heidelberg, Australia

\section{Results}

The HHA e-learning modules have been completed more than 800,000 times. The number of healthcare institutions submitting $\mathrm{HH}$ data increased from 290 in 2009 (262 public and 28 private institutions) to 828 in 2014 (535 public and 293 private). Over the same period, $\mathrm{HH}$ compliance increased from $61.8 \%$ (95\% confidence interval, 61.5-62.0) to $81.9 \%$ (95\% CI, 81.8-82.0). In 2014, $98 \%(814 / 828)$ of participating institutions met the $70 \%$ national benchmark. The incidence density of healthcareacquired Staphylococcus aureus bloodstream infection has decreased in parallel over the same period.

\section{Conclusion}

The NHHI has been a successful national quality improvement program. Key contributors to this success include leadership from the ACSQHC, a standardised national approach with collaboration between federal and jurisdictional authorities, adoption of WHO methodology, incorporation into hospital accreditation, and significant efforts from frontline infection control practitioners.

\section{Disclosure of interest}

None declared.

\section{Authors' details}

${ }^{1}$ Hand Hygiene Australia, Heidelberg, Australia. ${ }^{2}$ Australian Commission on Safety and Quality in Health Care, Darlinghurst, Australia.

Published: 16 June 2015

doi:10.1186/2047-2994-4-S1-046

Cite this article as: Stewardson et al:: Implementation of the Australian national hand hygiene initiative. Antimicrobial Resistance and Infection Control 2015 4(Suppl 1):046.

\footnotetext{
Full list of author information is available at the end of the article
}

(c) 2015 Stewardson et al; licensee BioMed Central Ltd. This is an Open Access article distributed under the terms of the Creative Commons Attribution License (http://creativecommons.org/licenses/by/4.0), which permits unrestricted use, distribution, and reproduction in any medium, provided the original work is properly cited. The Creative Commons Public Domain Dedication waiver (http://creativecommons.org/publicdomain/zero/1.0/) applies to the data made available in this article, unless otherwise stated. 